\section{Strangulated femoral hernia: the clinical trap}

Sir,

We read with interest the paper by Heys and Brittenden on 'Strangulated femoral hernia: the persisting clinical trap'. We have had 4 similar cases in the last year.

A 57 year old woman with a known history of inflammatory bowel disease presented to the medical ward with abdominal pain and vomiting. Examination and abdominal $\mathrm{X}$-rays were consistent with small bowel obstruction. However, the findings were attributed to an exacerbation of the patient's Crohn's disease, which had been clinically dormant for 6 years. Two days later, a surgical opinion revealed an irreducible and tender left femoral hernia. At operation, a small segment of necrotic small bowel was resected and there was no evidence of active Crohn's disease. The hospital stay was 19 days and the patient made a good recovery.

An obese 79 year old woman was referred to the duty surgical team with a 4-day history of abdominal pain and vomiting. She was taking ibuprofen for osteoarthritis, and her general practitioner treated her for gastritis/ peptic ulceration. On admission she had clinical and radiological evidence of small bowel obstruction with an irreducible right femoral hernia. Surgery was carried out urgently, and a segment of necrotic ileum was resected. Her recovery was complicated by chest and wound infections, and an ileus which lasted 7 days. The hospital stay was 24 days.

An 84 year old woman was referred from the geriatric department with a 5-day history of a tender swelling in the right groin. A diagnosis of lymphadenopathy was made and the patient investigated accordingly. However, worsening vomiting and abdominal pain precipitated referral to the surgeons who diagnosed a strangulated femoral hernia. Urgent surgery was undertaken with resection of a small bowel segment. The patient's recovery was complicated by chest infection and wound infection and breakdown. The hospital stay was 35 days.

A 92 year old woman was admitted with abdominal pain and vomiting. She had received laxatives for constipation several days prior to admission. On examination she was confused, dehydrated and had clinical and radiological evidence of small bowel obstruction with an irreducible right femoral hernia. At laparotomy, an ischaemic segment of small bowel was resected. The patient had a wound infection and was discharged home on the 36 th postoperative day.

The delay in establishing the diagnosis in these patients resulted in small bowel resection, increased morbidity and long hospital stay. The importance of examining hernial orifices as part of abdominal examination cannot be over-emphasized. Furthermore, a swelling in the groin should be considered as an irreducible hernia until proven otherwise, especially if accompanied by abdominal symptoms. The diagnosis of intestinal obstruction must be considered in the presence of abdominal pain and vomiting, and the persistence/worsening of these symptoms requires early surgical intervention.

H.T. Khawaja
N.D. Heaton
Department of Surgery,
Firm III office,
King's College Hospital,
Denmark Hill,
London SE5 9RS, UK.

\section{Reference}

1. Heys, S.D. \& Brittenden, J. Strangulated femoral hernia: the persisting clinical trap. Postgrad Med J 1991, 67: 57-59.

\section{Fenfluramine - induced irreversible pulmonary hypertension}

Sir,

Fenfluramine hydrochloride is a sympathomimetic agent used as an anorectic in the treatment of obesity. Fenfluramine has been implicated in drug-induced pulo

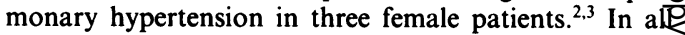
cases, symptoms disappeared after discontinuation of fenfluramine. We report a possible case of fenfluramine induced pulmonary hypertension in a young woman; in this case, however, the pulmonary hypertension appeared to be irreversible.

A 26 year old woman presented in December 1987 with a 3-month history of dyspnoea, orthopnoea and ankle swelling. In 1982, she had started using fenfluramine for weight reduction; her weight at that time had been $75 \mathrm{~kg}$ and height $155 \mathrm{~cm}$. In the subsequent 5 years, she had used the drug for several months intermittently $(60 \mathrm{mg}$ daily) and for 10 months continuously before admission (60-120 mg daily). On admission she weighed $107 \mathrm{~kg}$. Cardiovascular examination showed a blood pressure of $110 / 90 \mathrm{mmHg}$. On auscultation there was an atrial gallop rhythm; the pulmonary component of the second heart sound was accentuated and there was a palpable systolic pulsation in the second left intercostal space. A systolic murmur was heard along the left sternal border and there was also a holosystolic murmur of tricuspid regurgitation. The electrocardiogram showed sinus rhythm, right ventricular hypertrophy and $\mathrm{T}$ wave inversion and the chest radiograph slight cardiac enlargement with prominent main pulmonary arteries. Arterial blood gases showed a $\mathrm{PaO}_{2}$ of $58.7 \mathrm{mmHg}$ and a $\mathrm{PaCO}_{2}$ of $43.3 \mathrm{mmHg}$, $\mathrm{pH} 7.42$ and saturation $87.9 \%$. A ventilation/perfusion lung scan was normal. Echocardiogram (M-mode, 2D and Doppler) showed significant right atrial and right ventricular dilatation with overload of the right ventricle. 
Tricuspid valve incompetence and pulmonary regurgitation were detected with a calculated systolic right ventricular pressure of $60 \mathrm{mmHg}$. The contrast echo excluded an intra-cardiac shunt.

The M-mode echo of the pulmonary valve showed mid systolic notching in the posterior leaflet. The main stem of the pulmonary artery was dilated.

Right heart catheterization showed a pulmonary artery pressure of $80 / 37 \mathrm{mmHg}$ (mean 55). Left heart catheterization, left ventricular angiography and coronary arteriography were all entirely normal. The total pulmonary and the systemic arterial resistances both were significantly increased. The cardiac output was 3.83 litres/ $\mathrm{min}$ and the cardiac index $=1.96 \mathrm{litres} / \mathrm{min} / \mathrm{m}^{2}$.

The results confirmed the diagnosis of severe primary pulmonary hypertension. There was no evidence of collagen vascular disease. ${ }^{4}$ With treatment and a diet regimen, her body weight fell to $55 \mathrm{~kg}$, and her symptoms improved markedly. She was discharged in February 1988. Right heart catheterization was, therefore, repeated in February 1989 and the findings showed persistent pulmonary hypertension.

Reversible pulmonary hypertension has previously been reported in patients taking fenfluramine. ${ }^{2,3}$ One fatal case, with histological changes suggestive of irreversible pulmonary hypertension, has also been reported. ${ }^{5}$ While we have no histological confirmation, the persistence of pulmonary hypertension for more than 12 months is strongly suggestive of irreversible lung disease. It is, of course, possible that the consumption of fenfluramine and the development of pulmonary hypertension in this patient were coincidental. The appearance of a number of case reports from different centres, however, is at least suggestive of a causal association.

\section{Acknowledgements}

We would like to thank Dr E. Matsakas for technical assistance with echocardiography and Dr J. McLenachan and Mrs P. Jones for their assistance in preparing this manuscript.

I. Fotiadis

T. Apostolou

A. Koukoulas

N. Michelacakis

D. Kremastinos

Department of Cardiology, Athens General Hospital, 11527 Athens, Greece.

\section{References}

1. Martindale. The Extra Pharmacopoeia, 28th edition. The Pharmaceutical Press, London, 1982.

2. Douglas, J.G., Munro, J.F., Kitchin, A.H., Muir, A.L. \& Proudfoot, A.T. Pulmonary hypertension and fenfluramine. Br Med J 1981, 283: 881.

3. Gaul, G., Blazek, G., Deutsch, E. \& Heeger, H. Ein Fall von chronischer pulmonary Hypertonie nach Fenfluramineinnahme. Wien Klin Wochenschr 1982, 94: 618-622.

4. Hugles, J. \& Rubin, L. Primary pulmonary hypertension: an analysis of 28 cases and review of the literature. Medicine 1986, 65: $56-72$.

5. McMurray, J., Bloomfield, P. \& Miller, H.C. Irreversible pulmonary hypertension after treatment with fenfluramine. $B r$ Med J 1986, 292: 239-240.

\section{Serological prevalence of hepatitis $\mathrm{C}$ virus in a population of subjects with human immunodeficiency virus infection}

Sir,

The recent marketing ${ }^{1,2}$ of a serological test for the detection of the hepatitis $\mathrm{C}$ virus (HCV) led us to assess the prevalence of HCV in 120 human immunodeficiency virus (HIV)-infected patients.

The study population involved 95 men and 25 women whose mean age was 32.6 years (range: 18 to 61 years) with HIV positive serological test results as evidenced by the ELISA and Western blot methods. The risk factor for HIV infection was drug addiction and sexual intercourse, each in 60 patients. The latter included 39 homosexual or bisexual males. HCV serology (Ortho Diagnostics, ELISA) was positive in 57 patients $(47.5 \%), 47(80 \%)$ of whom were drug addicts and in $10(16.7 \%)$ patients who contracted HIV through sexual contact, a significant difference $(P<0.001$ Chi-square test). There was no statistically significant difference with respect to mean levels of serum gammaglobulin between $\mathrm{HCV}$ positive patients $(18.1 \pm 1.5 \mathrm{~g} / \mathrm{l})$ and those in $\mathrm{HCV}$ negative patients $(18.9 \pm 1.4 \mathrm{~g} / \mathrm{l})$. The presence of anti-HCV antibodies was significantly associated with that of one or more serological markers for the hepatitis B virus (HBV): 51 patients were $\mathrm{HBV}$-positive out of 57 with anti-HCV antibodies compared with 43 out of 63 patients with no antibodies $(P=\mathbf{0 . 0 0 2})$. Elevated alanine amino transferase levels were more frequently found $(75 \%)$ in the 52 patients with markers for both HCV and HBV than in the 42 patients with $\mathrm{HBV}$ infection only $(37.2 \% P<0.001)$.

Our study confirms the high serological prevalence of HCV in HIV seropositive patients, basically in the drug addict population. It does not provide evidence to support false positive results due to elevated serum gamma globulin levels, as has been suggested during certain types of chronic active hepatitis. ${ }^{3}$ In our series of patients, it appears that the presence of $\mathrm{HCV}$ is associated with the presence of a chronic liver disorder as evidenced by elevated transaminase levels. A possible correlation with histological lesions in the liver remains to be investigated.

A. Lafeuillade
C. Zandotti
C.Tamalet
R. Quilichini
J.A. Gastaut
Centre d'informations et dé soins
de l'immunodéficience humaine (CISIH),
Hôpital Salvator,
249 boulevard de Sainte Marguerite
13009 Marseille, France.

\section{References}

1. Kuo, G., Choo, Q.L., Alter, H.J. et al. An assay for circulating antibodies to a major etiologic virus of human non-A, non-B hepatitis. Science 1989, 244: 362-364.

2. Alter, H.J. \& Sampliner, R.E. Hepatitis C; and miles to go before we sleep. $N$ Engl J Med 1989, 321: 1538-1539.

3. McFarlane, I.G., Smith, H.M., Johnson, P.J. et al. Hepatitis C virus antibodies in chronic active hepatitis: pathogenic factor or false-positive results? Lancet 1990, 335: 754-757. 